\title{
Renewable Resources, Capital Accumulation, and Economic Growth
}

\author{
Wei-Bin Zhang \\ Ritsumeikan Asia Pacific University, \\ 1-1 Jumonjibaru, Beppu-Shi, Oita-ken, 874-8577 Japan \\ wbz1@apu.ac.jp
}

\begin{abstract}
This paper proposes a dynamic economic model with physical capital and renewable resources. Different from most of the neoclassical growth models with renewable resources which are based on microeconomic foundation and neglect physical capital accumulation, this study proposes a growth model with dynamics of renewable resources and physical capital accumulation. The model is a synthesis of the neoclassical growth theory and the traditional dynamic models of renewable resources with an alternative approach to household behavior. The model describes a dynamic interdependence among physical accumulation, resource change, and division of labor under perfect competition. Because of its refined economic structure, our study enables some interactions among economic variables which are not found in the existing literature on economic growth with renewable resources. We simulate the model to demonstrate the existence of equilibrium points and motion of the dynamic system. Our comparative dynamic analysis shows, for instance, that a rise in the propensity to consume the renewable resource increases the interest rate and reduces the national and production sector's capital stocks, wage rate and level of the consumption good. Moreover, it initially reduces and then increases the capital stocks of the resource sector and the consumption and price of the renewable resource. The stock of the renewable resource is initially increased and then reduced. Finally, labor is redistributed from the production to the resource sector.
\end{abstract}

Keywords: renewable resource, harvesting, capital accumulation, economic growth

Received 29 January 2011

Revised 5 April 2011

Accepted 25 April 2011

JEL Classification: D24, O41

Acknowledgements: The research has been financially supported by the the Grant-in-Aid for Scientific Research (C), Project No.: 21530246, Japan Society for the Promotion of Science.

\section{Introduction}

Renewable resources, such as forest or a fish species, are important for human life. Dynamic interdependence between economic growth and dynamics of renewable resource is an important topic in economic theory. This study attempts to make a contribution to the literature by examining interdependence between savings and dynamics of renewable resources with an alternative approach to consumers' behavior. The paper is organized as follows. Section 2 introduces the basic model with wealth accumulation and renewable resource dynamics. Section 3 examines dynamic properties of the model and simulates the model, identifying the existence of a unique equilibrium and checking the stability conditions. Section 4 studies effects of changes in some parameters on the system. Section 5 concludes the study. The appendix proves the analytical results in Section 3.

\section{The basic model}

The economy has one production sector and one resource sector. Most aspects of the production sector are similar to the standard one-sector growth model (Burmeister and Dobell 1970, Barro and Sala-i-Martin, 1995). It is assumed that there are only one (durable) good and one renewable resource in the economy under consideration. Households own capital of the economy and distribute their incomes to consume the commodity and renewable resource and to save. Exchanges take place in perfectly competitive markets. We assume a homogenous and fixed population. The labor force is distributed between the two sectors. We select commodity to serve as numeraire (whose price is normalized to 1), with all the other prices being measured relative to its price. 


\subsection{The production sector}

We assume that production is to combine labor force, $\mathrm{N}_{\mathrm{i}}(\mathrm{t})$, and physical capital, $\mathrm{K}_{\mathrm{i}}(\mathrm{t})$. We use the conventional production function to describe a relationship between inputs and output. The production function is specified as follows

$$
F_{i}(t)=A_{i} K_{i}^{\alpha_{i}}(t) N_{i}^{\beta_{i}}(t), A_{i}, \alpha_{i}, \beta_{i}>0, \alpha_{i}+\beta_{i}=1
$$

where $F_{i}(t)$ is the output level of the production sector at time $t$ and $A_{i}, \alpha_{i}$ and $\beta_{i}$ are parameters. Markets are competitive; thus labor and capital earn their marginal products. The rate of interest, $r(t)$, and wage rate, $w(t)$, are determined by markets. The marginal conditions are given by

$$
r(t)+\delta_{k}=\frac{\alpha_{i} F_{i}(t)}{K_{i}(t)}, w(t)=\frac{\beta_{i} F_{i}(t)}{N_{i}(t)}
$$

where $\delta_{k}$ is the given depreciation rate of physical capital, $0 \leq \delta_{k}<1$.

\subsection{Change of renewable resources}

Let $\mathrm{X}(\mathrm{t})$ stand for the stock of the renewable resource. The natural growth rate of the resource is assumed to be a logistic function of the existing stock

$$
\phi_{0} \mathrm{X}(\mathrm{t})\left(1-\frac{\mathrm{X}(\mathrm{t})}{\phi}\right), \phi_{0}, \phi>0,
$$

where the variable, $\phi$, is the maximum possible size for the resource stock, called the carrying capacity of the resource, and the variable, $\phi_{0}$, is "uncongested" or "intrinsic" growth rate of the renewable resource. The logistic model has been frequently used in the literature of growth with renewable resource (Brander and Taylor, 1998; Hannesson, 2000; Cairns and Tian, 2010). If the stock is equal to $\phi$, then the growth rate should equal zero. If the carrying capacity is much larger than the current stock, then the growth rate per unit of the stock is approximately equal to the intrinsic growth rate. That is, the congestion effect is negligible. In this study, for simplicity we assume both the carrying capacity and the intrinsic growth rate constant. This is a strict assumption as the two variables may change due to changes in other conditions. For instance, in Jinji (2006), the carrying capacity changes as a function of the stock of a renewable resource. Let $\mathrm{F}_{\mathrm{x}}(\mathrm{t})$ stand for the harvest rate of the resource. The change rate in the stock is then equal to the natural growth rate minus the harvest rate, that is

$$
x^{\&}(\mathrm{t})=\phi_{0} x(\mathrm{t})\left(1-\frac{\mathrm{x}(\mathrm{t})}{\phi}\right)-\mathrm{F}_{\mathrm{x}}(\mathrm{t}) .
$$

We now examine functional form of the harvest rate. We assume a nationally owned open-access renewable resource (Gordon, 1954). With open access, harvesting occurs up to the point at which the current return to a representative entrant equals the entrant's cost. This condition may not be satisfied, for instance, when property rights of the 
resource are incomplete. Aside from the stock of the renewable resources, like the good sector there are two factors of production. Let $\mathrm{N}_{\mathrm{x}}(\mathrm{t})$ and $\mathrm{K}_{\mathrm{x}}(\mathrm{t})$ stand for, respectively, labor force and capital stocks employed by the resource sector. We assume that harvesting of the resource is carried out according to the following harvesting production function

$$
F_{x}(t)=A_{x} x^{b}(t) K_{x}^{\alpha_{x}}(t) N_{x}^{\beta_{x}}(t), A_{x}, b \geq 0, \alpha_{x}, \beta_{x}>0, \alpha_{x}+\beta_{x}=1,
$$

where $A_{x}, b, \alpha_{x}$ and $\beta_{x}$ are parameters. The specified form implies that if the capital (like machine) and labor inputs are simultaneously doubled, then harvest is also doubled for a given stock of the resource at a given time. The Schaefer harvesting production function which is taken on the following form (Schaefer, 1957):

$$
F_{x}(t)=A_{x} X(t) N_{x}(t)
$$

is a special case of (4) if we let $\alpha_{x}=0$. The function with fixed capital and technology is widely applied to fishing (Paterson and Wilen, 1977; Milner-Gulland and Leader-Williams, 1992; Bulter and van Kooten, 1999). The Schaefer production function does not take account of physical capital (or with capital being fixed). As machines are important inputs in harvesting, we explicitly take account of capital inputs.

Harvesting is carried out by competitive profit-maximizing firms under conditions of free entry. Let $\mathrm{p}(\mathrm{t})$ stand for the price of the stock. Then the profit is given by

$$
p(t) F_{x}(t)-\left(r(t)+\delta_{k}\right) K_{x}(t)-w(t) N_{x}(t)
$$

Firms choose the capital and labor inputs. The marginal conditions are given as follows

$$
r(t)+\delta_{k}=\frac{\alpha_{x} p(t) F_{x}(t)}{k_{x}(t)}, w(t)=\frac{\beta_{x} p(t) F_{x}(t)}{N_{x}(t)} .
$$

Let $\mathrm{N}$ and $\mathrm{K}(\mathrm{t})$ stand for respectively the (fixed) the population and total capital stock. The labor force is allocated between the two sectors. As full employment of labor and capital is assumed, we have

$$
\mathrm{K}_{\mathrm{i}}(\mathrm{t})+\mathrm{K}_{\mathrm{x}}(\mathrm{t})=\mathrm{K}(\mathrm{t}), \quad \mathrm{N}_{\mathrm{i}}(\mathrm{t})+\mathrm{N}_{\mathrm{x}}(\mathrm{t})=\mathrm{N}
$$

\subsection{Consumer's behavior}

Consumers make decisions on choice of consumption levels of the resource good and commodities as well as on how much to save. We apply an alternative approach to preference structure of consumers over consumption and saving. We denote per capita wealth by $\mathrm{k}(\mathrm{t})$, where $\mathrm{k}(\mathrm{t}) \equiv \mathrm{K}(\mathrm{t}) / \mathrm{N}$. Per capita current income from the interest payment $r(t) k(t)$ and the wage payment $w(t)$ is given by 


$$
y(t)=r(t) k(t)+w(t)
$$

We call $\mathrm{y}(\mathrm{t})$ the current income. The per capita disposable income is given by

$$
\hat{y}(t)=y(t)+k(t)=(1+r(t)) k(t)+w(t)
$$

The disposable income is used for saving and consumption. At each point of time, a consumer would distribute the total available budget among saving, $\mathrm{s}(\mathrm{t})$, consumption of the commodity, $\mathrm{c}(\mathrm{t})$, and consumption of the resource good, $c_{x}(t)$. The budget constraint is given by

$$
c(t)+s(t)+p(t) c_{x}(t)=\hat{y}(t)
$$

In our model, at each point of time, consumers have three variables, $\mathrm{s}(\mathrm{t}), \mathrm{c}(\mathrm{t})$, and $\mathrm{c}_{\mathrm{x}}(\mathrm{t})$, to decide. We assume that consumers' utility function is a function of $s(t), c(t)$, and $c_{x}(t)$, as follows

$$
\mathrm{U}(\mathrm{t})=\mathrm{U}\left(\mathrm{c}(\mathrm{t}), \mathrm{s}(\mathrm{t}), \mathrm{c}_{\mathrm{x}}(\mathrm{t})\right)
$$

For simplicity of analysis, we specify the utility function as follows

$$
U(t)=c^{\xi_{0}}(t) s^{\lambda_{0}}(t) c_{x}^{\chi_{0}}(t), \xi_{0}, \lambda_{0}, \chi_{0}>0,
$$

where $\xi_{0}$ is called the propensity to consume, $\lambda_{0}$ the propensity to own wealth, and $\chi_{0}$ the propensity to consume the resource good. A detailed explanation of the approach and its applications to different problems of economic dynamics are provided in Zhang (2005). For the representative consumer, wage rate $w(t)$ and rate of interest $r(t)$ are given in markets and wealth $k(t)$ is predetermined before decision. Maximizing $U(t)$ in (9) subject to budget constraint (8) yields

$$
c(t)=\xi \hat{y}(t), \quad s(t)=\lambda \hat{y}(t), \quad p c_{x}(t)=\chi \hat{y}(t)
$$

where

$$
\xi \equiv \rho \xi_{0}, \lambda \equiv \rho \lambda_{0}, \chi \equiv \rho \chi_{0}, \rho \equiv \frac{1}{\xi_{0}+\lambda_{0}+\chi_{0}} .
$$

The demand for the resource good is given by $c_{x}=\chi \hat{y} / p$. The demand decreases in its price and increases in the disposable income. An increase in the propensity to consume the resource good increases the consumption when the other conditions are fixed. In this dynamic system, as any factor is related to all the other factors over time, it is difficult to see how one factor affects any other variable over time in the dynamic system.

We now find dynamics of capital accumulation. According to the definition of $s(t)$, the change in the household's wealth is given by 


$$
k(t)=s(t)-k(t)
$$

The equation simply states that the change in wealth is equal to saving minus dissaving. The demand for and supply of the resource balance at any point of time

$$
C_{x}(t) N=F_{x}(t)
$$

As output of the production sector is equal to the sum of the level of consumption, the depreciation of capital stock and the net savings, we have

$$
\mathrm{C}(\mathrm{t})+\mathrm{S}(\mathrm{t})-\mathrm{K}(\mathrm{t})+\delta_{\mathrm{k}} \mathrm{K}(\mathrm{t})=\mathrm{F}_{\mathrm{i}}(\mathrm{t})
$$

where $\mathrm{C}(\mathrm{t})$ is the total consumption, $\mathrm{S}(\mathrm{t})-\mathrm{K}(\mathrm{t})+\delta_{\mathrm{k}} \mathrm{K}(\mathrm{t})$ is the sum of the net saving and depreciation. We have

$$
C(t)=c(t) N, S(t)=s(t) N
$$

We now show that equation (13) can be derived from the other equations in the system. First, multiplying (8) with $\mathrm{N}$ and then inserting the (7) in the resulted equation, we get

$$
C+S-K=w N+r N-p F_{x}
$$

where we also use (12). From the marginal conditions for the two sectors and (6), we have

$$
w N+r K-p F_{x}=F_{i}-\delta_{k} K .
$$

The above two equations imply (13). We have thus built the dynamic model. We now examine dynamics of the model.

\section{The dynamics and its properties}

This section examines dynamics of the model. First, we introduce a new variable by $z(t) \equiv K_{i}(t) / K_{x}(t)$. We now show that the dynamics of the economic system can be expressed by the two-dimensional differential equations system with $\mathrm{z}(\mathrm{t})$ and $\mathrm{X}(\mathrm{t})$ as the variables.

\section{Lemma 1}

The economy is governed by the 2 -dimensional differential equations 


$$
\begin{aligned}
& \&=[\lambda N \hat{y}(z)-\Lambda(z)]\left(\frac{d \Lambda}{d z}\right)^{-1}, \\
& \&=\phi_{0} x\left(1-\frac{x}{\phi}\right)-F_{x}(z, x),
\end{aligned}
$$

where the functions in (14) are functions of $z(t)$ and $X(t)$ explained in the appendix. Moreover, all the other variables can be determined as functions of $z(t)$ and $X(t)$ at any point of time by the following procedure: $K$ by (A9) $\rightarrow K_{i}$ and $\mathrm{K}_{\mathrm{x}}$ by $(\mathrm{A} 2) \rightarrow \mathrm{N}_{\mathrm{i}}$ and $\mathrm{N}_{\mathrm{x}}$ by (A3) $\rightarrow \mathrm{F}_{\mathrm{i}}$ by (1) $\rightarrow \mathrm{r}$ and $\mathrm{W}$ by (2) $\rightarrow \mathrm{F}_{\mathrm{x}}$ by (4) $\rightarrow \mathrm{p}$ by (5) $\rightarrow \hat{\mathrm{y}}$ by $(7) \rightarrow$ $C_{1}, C_{x}$ and $s$ by (10).

We now show that the economic system has a unique stable equilibrium point. The differential equations system (14) contains two variables $\mathrm{z}(\mathrm{t})$ and $\mathrm{X}(\mathrm{t})$. A steady state is determined by

$$
\begin{aligned}
& \lambda N \hat{y}(z)-\Lambda(z)=0, \\
& \phi_{0} \times\left(1-\frac{x}{\phi}\right)-A_{x} \times{ }^{b} K_{x}^{\alpha_{x}} N_{x}^{\beta_{x}}=0 .
\end{aligned}
$$

The first equation contains a single variable, $z$. From (15) and (A9), we have

$$
r+\frac{w N}{K}=\frac{1}{\lambda}-1
$$

where we also use (7). Substituting (2) into (17) yields

$$
\left(\alpha_{i}+\beta_{i} \frac{z+\alpha}{z+1}\right)\left(\frac{z+1}{z+\alpha}\right)^{\beta_{i}}=\frac{K^{\beta_{i}}}{A_{i} N^{\beta_{i}}}\left(\frac{1}{\lambda}-\delta\right)
$$

where we use (1), (A2), (A3), and $\delta \equiv 1-\delta_{k}$. From (18) and (A9), we have

$$
\mathrm{z}=\frac{\overline{\mathrm{n}}_{0} \mathrm{n}_{1}-\alpha_{\mathrm{i}}-\alpha \beta_{\mathrm{i}}}{1+\overline{\mathrm{n}}_{0} \mathrm{n}_{2}}=\frac{1}{1+\overline{\mathrm{n}}_{0} \mathrm{n}_{2}} \frac{\alpha_{\mathrm{i}}}{\alpha_{\mathrm{x}}} \frac{1-\lambda \delta-\chi}{\lambda \delta \chi},
$$

where

$$
\bar{n}_{0} \equiv \frac{n_{0}^{\beta_{i}}}{A_{i} N^{\beta_{i}}}\left(\frac{1}{\lambda}-\delta\right)=\left(\frac{\beta_{i}}{\beta_{x} \delta}\right)\left(\frac{1}{\lambda}-\delta\right)>0 .
$$

As $1-\lambda \delta-\chi>0$, therefore $z>0$. As we solved $z$, we also obtain $K_{1}, K_{x}$ and $\mathrm{N}_{x}$ as functions of $z$. Hence, from (16), we determine $X$ as

$$
X+A_{0} X^{b-1}-\phi=0
$$

where 


$$
A_{0}=\frac{\phi A_{x} K_{x}^{\alpha_{x}} N_{x}^{\beta_{x}}}{\phi_{0}}
$$

We can obtain explicit solution, for instance, when $b=0,1 / 2$, or 1 . Here, we assume $b=1$ as, for instance, in Brander and Taylor (1997). We have

$$
X=\phi-A_{0} .
$$

We require the solution to be positive. We don't explain the conditions for the solution to be positive as it is difficult to explicitly interpret. We will check the conditions by simulation.

To calculate the eigenvalues, we need to explicitly know $\hat{y}(z(t))$ in the dynamic system. From (A4) and (A6), we have

$$
\hat{y}(z)=\frac{\delta \Lambda}{\chi N}\left[\frac{1}{\chi}-(1+z) \alpha_{x}-\frac{(z+\alpha) \beta_{x}}{\alpha}\right]^{-1} .
$$

We calculate the two eigenvalues as follows

$$
\begin{aligned}
& \frac{\alpha_{\mathrm{x}}}{\alpha_{\mathrm{i}}}\left[\frac{1}{\chi}-(1+\mathrm{z}) \alpha_{\mathrm{x}}-\frac{(\mathrm{z}+\alpha) \beta_{\mathrm{x}}}{\alpha}\right]^{-2} \frac{\lambda \delta \Lambda}{\chi}\left(\frac{\mathrm{d} \Lambda}{\mathrm{dz}}\right)^{-1}<0, \\
& -\frac{\phi_{0} \mathrm{x}}{\phi}<0,
\end{aligned}
$$

where we use $d \Lambda / d z<0$. Hence, the unique steady state is stable.

\section{Lemma 2}

The economic system has a unique stable equilibrium point.

As the expressions of the analytical results are tedious, for illustration we specify the parameter values and simulate the model. We specify the parameters as follows

$$
\begin{aligned}
& N_{0}=5, \quad \alpha_{i}=0.3, A_{i}=1, \alpha_{x}=0.4, A_{x}=0.5, \phi=1, \phi_{0}=6, \\
& \lambda_{0}=0.6, \quad \xi_{0}=0.15, \chi_{0}=0.06, \delta_{k}=0.05 .
\end{aligned}
$$

The capacity is unity and the adjustment speed, $\phi_{0}$, is fixed at 6 . By simulation we can demonstrate that for the given values of the other parameters, if $\phi_{0}$ is too large or too small, then the system may not have a positive equilibrium point. The population is fixed at 5 . Because of the model's properties of constant returns to scale, the population size has no impact on the prices and labor distribution ratio. The propensity to save is much higher than the propensity to consume the commodity and the propensity to consume the renewable resource. 
Under (23), the equilibrium values are given as in (24).

$$
\begin{aligned}
& K=18.55, X=0.82, F_{i}=5.57, F_{X}=0.88, N_{i}=3.89, N_{X}=1.11, K_{i}=12.84, K_{x}=5.71, p=2.11, r=0.08, \\
& W=1.00, C_{X}=0.18, C=0.83(24)
\end{aligned}
$$

It should be noted that as $s=\lambda c / \xi$ at any point of time, we don't plot the motion of $s$. The two eigenvalues are -4.93 and -0.20 . This guarantees the stability of the steady state. Hence, the dynamic system has a unique stable steady state. With the initial conditions, $z(0)=1.5$ and $X(0)=0.5$, we plot the motion of the system as in Figure 1 . We see that the level of the resource stocks is increased and its price falls over time. The capital and labor force employed by the resource sector fall over time.

Figure 1: Motion of the Economic System
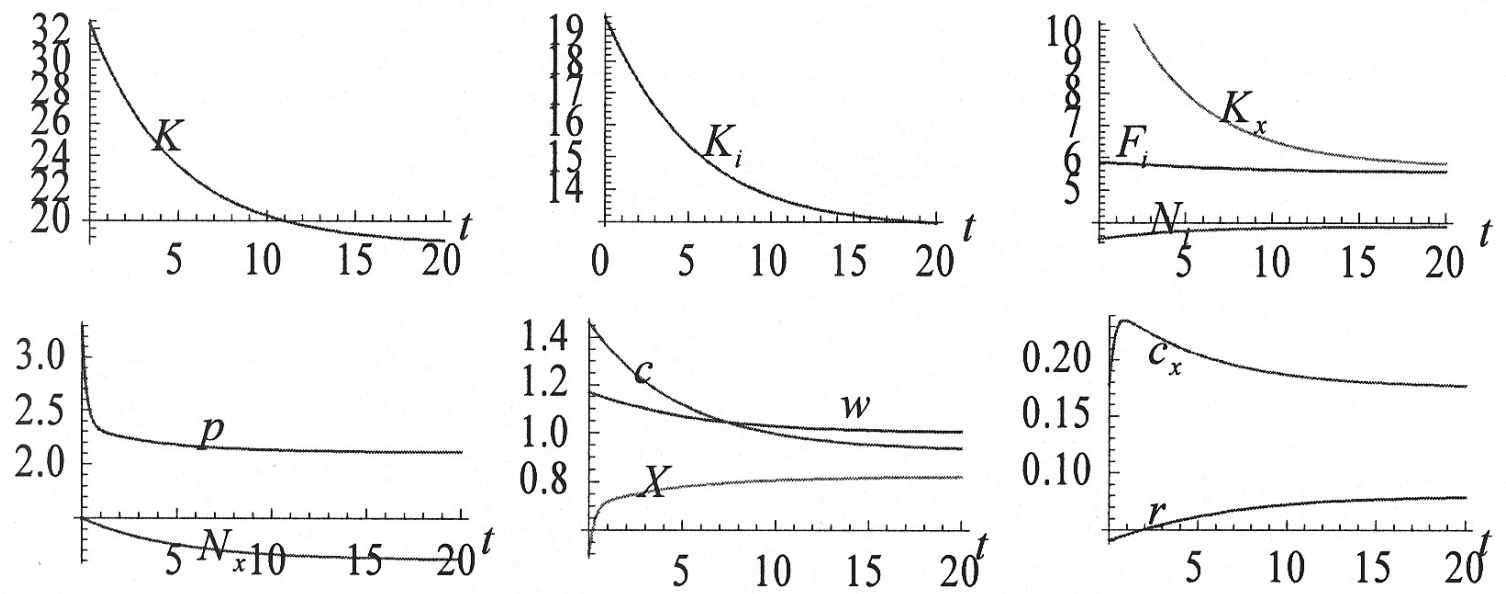

\section{Comparative dynamic analysis}

This section examines effects of changes in some parameters on the motion of the economic system. First, we study the case that all the parameters, except the propensity to consume the resource are the same as in (23). We increase the propensity in the following way: $\chi_{0}: 0.06 \Rightarrow 0.065$. The simulation results are demonstrated in Figure 2 . In the plots, a variable $\bar{\Delta} \mathrm{x}(\mathrm{t})$ stands for the change of the variable $\mathrm{x}(\mathrm{t})$ in percentage due to changes in the parameter value. We will use the symbol $\bar{\Delta}$ with the same meaning when we analyze other parameters. The rise in the propensity to consume the resource reduces the national and production sector's capital stocks, wage rate and level of the consumption good, increases the interest rate; reduces initially and then increases the capital stocks of the resource sector and the consumption and price of the renewable resource; increases initially and then reduces the stock of the renewable resource; redistributes the labor distribution from the production sector to the resource sector. 
Figure 2: A Rise in the Propensity to Consume the Resource
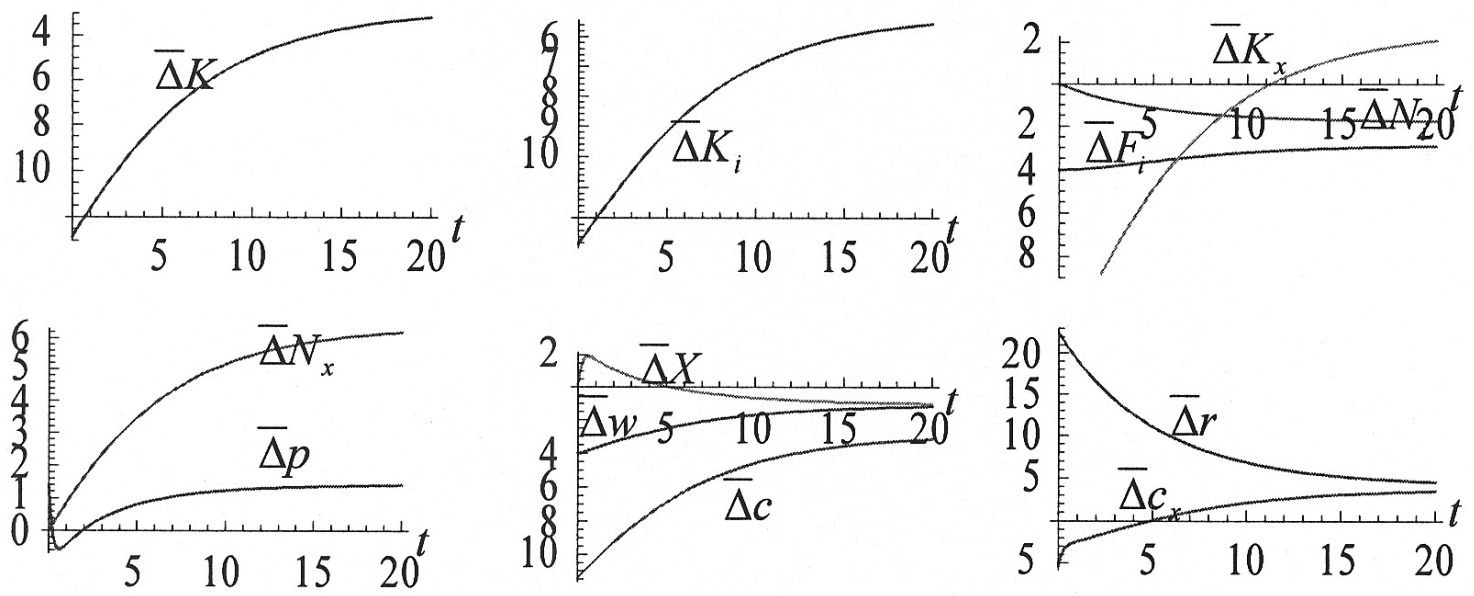

We now increase the propensity to consume the commodity in the following way: $\xi_{0}: 0.15 \Rightarrow 0.16$. We see that in the long term the rates of interest, the consumption level of the commodity, the stock of the resource, and the labor force in the production sector are increased, the values of the other shown variables are reduced. The rise in the propensity to consume the commodity increases the stock of the resource and reduces the consumption level of the resource.

Figure 3: A Rise in the Propensity to Consume the Commodity
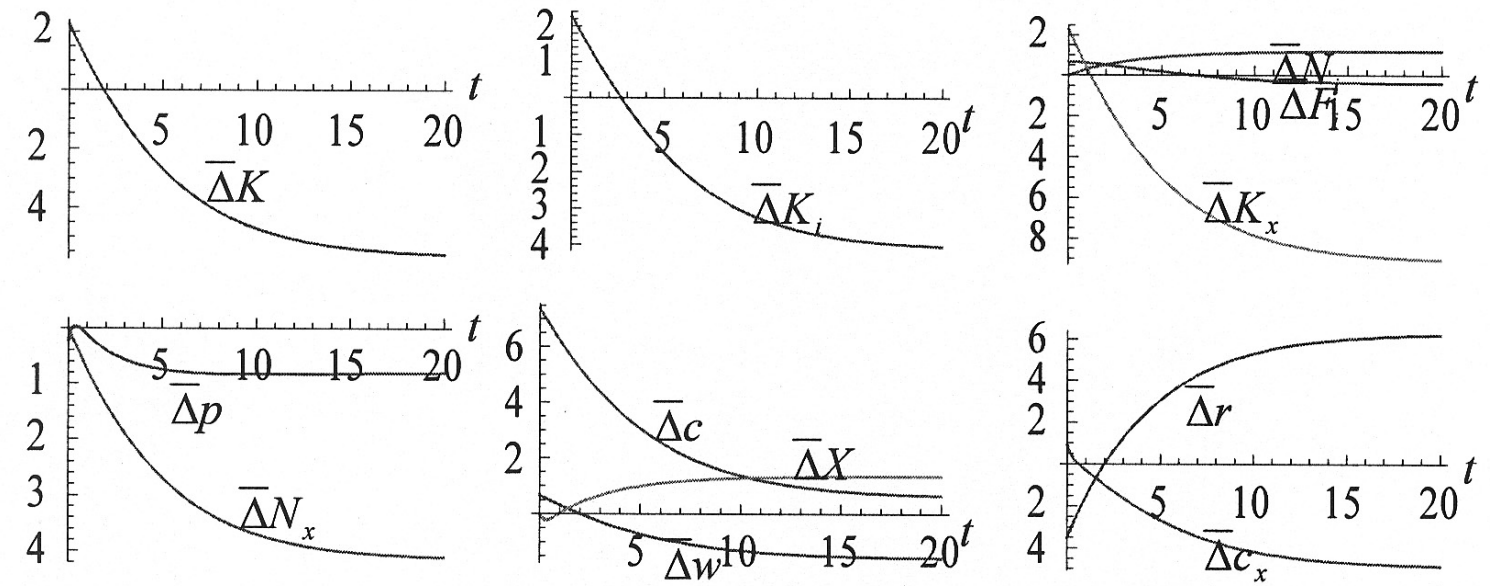

We now increase the propensity to save in the following way: $\lambda_{0}: 0.6 \Rightarrow 0.65$. In the long term the rate of interest, the national wealth and output level of the commodity sector are increased. The rise in the propensity to save reduces the price, the labor force employed by the resource sector, the stock of the resource and the consumption level of the resource, but increases the capital stocks employed by the sector. 
Figure 4: A Rise in the Propensity to Save
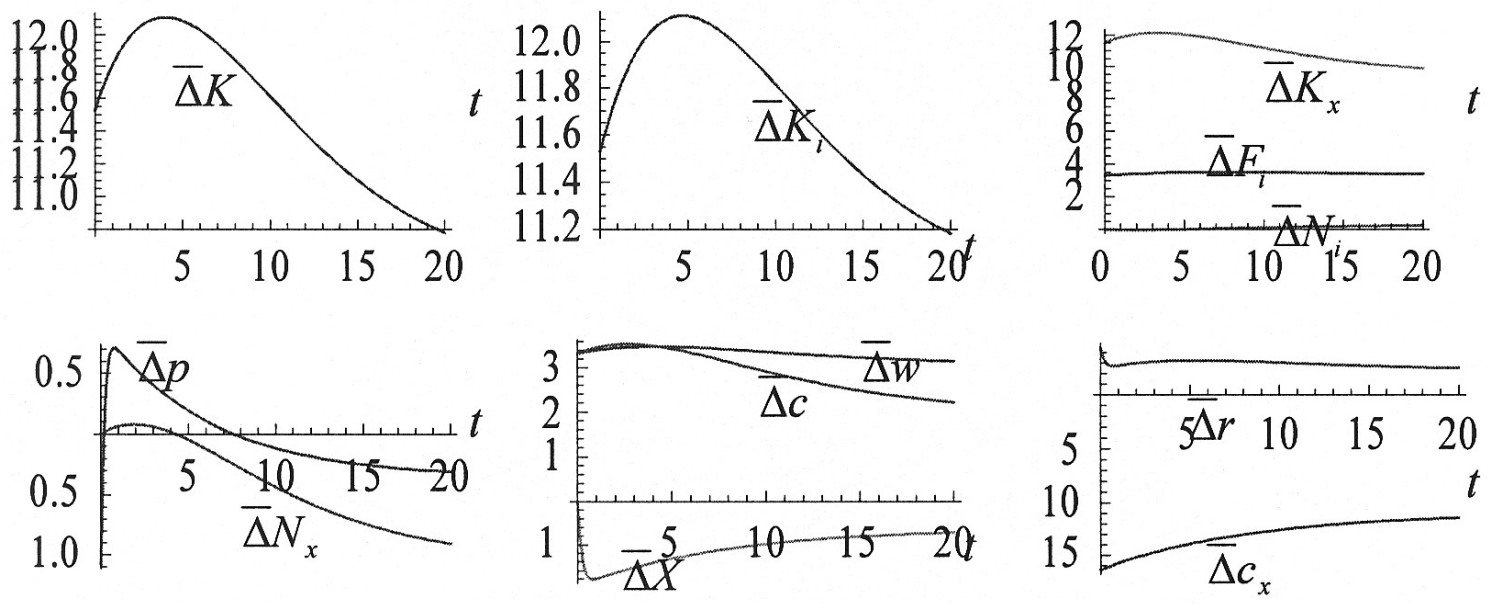

\section{Concluding Remarks}

This paper proposed a dynamic economic model with physical capital and renewable resources. Different from most of the neoclassical growth models with renewable resources based on microeconomic foundation which neglect physical capital accumulation, our model examines dynamics of renewable resources and physical capital accumulation. The model is a synthesis of the neoclassical growth theory and the traditional dynamic models of renewable resources with an alternative approach to household behavior. The model describes a dynamic interdependence among physical accumulation, resource change, and division of labor under perfect competition. Because of its refined economic structure, our study provides some interactions among economic variables which are not found in the existing literature of economic growth with renewable resources. We simulated the model to demonstrate existence of equilibrium points and motion of the dynamic system. We may extend the model in some directions. For instance, we may introduce some kind of government intervention in the resource sector. It is also desirable to treat leisure time as an endogenous variable.

\section{Appendix: Proving Lemma 1}

We now show that the dynamics can be expressed by a two-dimensional differential equations system. From (2) and (5), we obtain

$$
\mathrm{z}=\frac{\mathrm{K}_{\mathrm{i}}}{\mathrm{K}_{\mathrm{x}}}=\alpha \frac{\mathrm{N}_{\mathrm{i}}}{\mathrm{N}_{\mathrm{x}}}
$$

where we omit time index and $\alpha \equiv \beta_{\mathrm{x}} \alpha_{\mathrm{i}} / \alpha_{\mathrm{x}} \beta_{\mathrm{i}}$. By (A1) and (6), we solve

$$
\begin{aligned}
& K_{i}=\frac{z K}{z+1}, K_{x}=\frac{K}{z+1} \\
& N_{i}=\frac{z N}{z+\alpha}, \quad N_{x}=\frac{\alpha N}{z+\alpha} .
\end{aligned}
$$


By (12) and $p c_{x}=\chi \hat{y}$ in (10), we have

$$
\chi N \hat{y}=p F_{x} .
$$

By the definition of $\hat{y}$, we have

$$
N \hat{y}=\left(\delta+\frac{\alpha_{x} p F_{x}}{K_{x}}\right) K+\frac{\beta_{x} p F_{x} N}{N_{x}}
$$

where we use (5) and $\delta \equiv 1-\delta_{k}$. Insert (A5) in (A4)

$$
\left[\frac{1}{\chi}-(1+z) \alpha_{x}-\frac{(z+\alpha) \beta_{x}}{\alpha}\right] p F_{x}=\delta K \text {, }
$$

where we also use (A2) and (A3). From (2) and (5), we solve

$$
p F_{x}=\frac{\beta_{i} N_{x} F_{i}}{\beta_{x} N_{i}}
$$

Substituting (A7) into (A6) yields

$$
\left[\frac{1}{\chi}-(1+z) \alpha_{x}-\frac{(z+\alpha) \beta_{x}}{\alpha}\right] \frac{\alpha \beta_{i} F_{i}}{\beta_{x} z}=\delta K,
$$

where we use (A1). Substituting (1), (A3) and (A2) into (A8), we solve

$$
K=\Lambda(z) \equiv\left(\frac{1}{z+1}\right)^{\alpha_{i} / \beta_{i}} \frac{n_{0}\left(n_{1}-n_{2} z\right)^{1 / \beta_{i}}}{z+\alpha}
$$

where

$$
\mathrm{n}_{0} \equiv \mathrm{N}\left(\frac{\beta_{\mathrm{i}} \mathrm{A}_{\mathrm{i}}}{\beta_{\mathrm{x}} \delta}\right)^{1 / \beta_{\mathrm{i}}}>0, \mathrm{n}_{1} \equiv \frac{\alpha}{\chi}-\alpha>0, \mathrm{n}_{2} \equiv \alpha \alpha_{\mathrm{x}}+\beta_{\mathrm{x}}=\frac{\beta_{\mathrm{x}}}{\beta_{\mathrm{i}}}>0 .
$$

We require $n_{1}-n_{2} z$ positive for $K$ to be meaningful. We express $K$ as a function of $z$. From (A2), $K_{i}$ and $K_{x}$ are functions of $z$. From (A3), $N_{i}$ and $N_{x}$ are functions of $z$. By the following procedure, we can express other variables as functions of $z(t)$ and $X(t)$ at any point of time: $F_{i}$ by (1) $\rightarrow r$ and $W$ by (2) $\rightarrow F_{x}$ by (4) $\rightarrow p$ by (5) $\rightarrow \hat{y}$ by $(7) \rightarrow C, C_{x}$ and $S$ by (10). Notice that only $F_{x}, P$ and $C_{x}$ depend both on $\mathbf{Z}$ and $X$.

Taking derivatives of (A9) with respect to $t$ yields

$$
k^{\&}=\frac{\mathrm{d} \Lambda}{\mathrm{d} z} \&
$$

where 


$$
\frac{d \Lambda}{d z}=-\left[\frac{\alpha_{i}}{\beta_{i}(z+1)}+\frac{1}{z+\alpha}+\frac{n_{2}}{\beta_{i}\left(n_{1}-n_{2} z\right)}\right] \Lambda<0 .
$$

We see that as $\mathrm{K}$ rises, $\mathbf{z}$ falls. This implies that as the economy accumulates more physical wealth, the ratio between the capitals employed by the good sector and the resource sector is reduced.

Multiplying the two sides of (11) with $\mathrm{N}$ and using (10), we have

$$
k^{\&}=\lambda N \hat{y}(z)-K
$$

Substituting (A10) and $\mathrm{K}=\Lambda(\mathrm{z})$ into the above function, we get the differential equation for $\mathrm{Z}$ in (14). We have thus proved Lemma 1.

\section{References}

1. Barro, R.J., Sala-i-Martin, X. (1995). Economic Growth. New York: McGraw-Hill, Inc.

2. Brander, J.A., Taylor, M.S. (1998). The Simple Economics of Easter Island: A Ricardo-Malthus Model of Renewable Resource Use. American Economic Review 81, 119-38.

3. Bulter, E.H., Van Kooten, G.C. (1999). Economics of Antipoaching Enforcement and the Ivory Trade Ban. American Journal of Agricultural Economics 81, 453-66.

4. Burmeister, E., Dobell, A.R. (1970). Mathematical Theories of Economic Growth. London: Collier Macmillan Publishers.

5. Cairns, D.R., Tian, H.L. (2010). Sustained Development of a Society with a Renewable Resource. Journal of Economic Dynamics \& Control 24, 2048-61.

6. Gordon, H.S. (1954). The Economic Theory of a Common Property Resource: The Fishery. Journal of Political Economy 62, 124-42.

7. Hannesson, R. (2000). Renewable Resources and the Gains From Trade. Canadian Journal of Economics 33, 122-32.

8. Jinji, N. (2006). International Trade and Terrestrial Open-Access Renewable Resources in a Small Open Economy. Canadian Journal of Economics 39, 790-808.

9. Milner-Gulland, E.J., Leader-Williams, N. (1992). A Model of Incentives for the Illegal Exploitation of Black Rhinos and Elephants. Journal of Applied Ecology 29, 388-401.

10. Paterson, D.G., Wilen, J.E. (1977). Depletion and Diplomacy: The North-Pacific Seal Hunt, 1880-1910, in Uselding, P. (Ed.) Research in Economic History. Connecticut: JAI Press.

11. Schaefer, M.B. (1957). Some Considerations of Population Dynamics and Economics in Relation to the Management of Marine Fisheries. Journal of Fisheries Research Board of Canada 14, 669-81.

12.Zhang, W.B. (2005). Economic Growth Theory. London: Ashgate.

Wei-Bin Zhang, PhD (Umeå, Sweden), is Associate Dean of Graduate School of Management, Professor (since 2000 till now) in Ritsumeikan Asia Pacific University (APU), Japan. He graduated in 1982 from Department of Geography, Beijing University, China, and completed graduate study at Department of Civil Engineering, Kyoto University, Japan. After he completed his dissertation on economic growth theory under supervision of Prof. Ake E Andersson with Prof. Michio Morishima as the main examiner, he researched at the Swedish Institute for Futures Studies in Stockholm for 10 years. He also worked as visiting scholars in USA, Japan, Mainland China, Austria, Singapore and Hong Kong. His main research fields are nonlinear economic dynamics, growth theory, trade theory, East Asian economic development, and Confucianism. He has published about 200 academic articles (95 in peer-review international journals), authorized 22 academic books in English by international publishing houses. Prof. Zhang is editorial board members of 7 peer-review international journals. 